This month's Airwaves takes its cue from the "Good Vibrations" editorial on page 296 , to bring you a musically themed Airwaves. Our editorial highlights with segue effortlessly from respiratory medicine to the "Rock and Roll" Hall of Fame and back again...

\section{GOOD VIBRATIONS}

When it was released in 1966, this three and a half minute track by the Beach Boys was the costliest single ever recorded and was more than 6 months in the making. The good vibrations in this month's Thorax are less costly but took rather longer to complete. Mok and colleagues (see page 331) describe a randomised, crossover trial of a convenient vibratory positional device vs continuous positive airways pressure (CPAP), in 40 patients with positional obstructive sleep apnoea. The device significantly reduced the time participants spent lying on their backs (vs CPAP). However the intervention failed to meet the noninferiority limit for the primary outcome of Epworth Sleepiness Scale. "Good Vibrations" entered the Rock and Roll Hall of Fame's "500 Songs that Shaped Rock and Roll." More work is needed on vibratory positional devices, if they are to enter the sleep medicine hall of fame.

\section{CIGARETTES \& ALCOHOL}

Released almost thirty years after "Good Vibrations," the single "Cigarettes \& Alcohol" by Oasis has a rather nihilistic philosophy: "... all I need are cigarettes and alcohol!” Driving whilst under the influence of alcohol has been illegal for decades but smoking while children are in the car was not banned in England until 2015 (2016 in Scotland). In the journal this month, Laverty et al (see page 345) describe the effects of the ban on smoking in cars on self-reported smoke exposure by 13 to 15 year olds. In England, exposure was reduced from $6.3 \%$ to $1.6 \%$ and in Scotland from $3.4 \%$ to $1.3 \%$. An accompanying commentary (see page 297) suggests that careful scrutiny of the effects of vaping in cars, while children are present, is now warranted. Oasis have not yet entered the Rock and Roll Hall of Fame and the continuing acrimony between the Gallagher brothers makes a comeback unlikely. Equally unlikely is a comeback for smoking in cars with children, as evidence of the beneficial effects of the ban accumulates.

\section{THE KING}

Elvis Aaron Presley is regarded as one of the most significant cultural icons of the 20th century and he was bestowed the title of the "King of Rock and Roll". However, his change in body composition from the age of 20 to his early death at the age of 42 , fuelled by his reported consumption of a 42000 calories $30 \mathrm{~cm}$ long bacon, peanut butter and strawberry jam bread roll, may have been the inspiration for the study of Gabriela Peralta and colleagues (see page 313) reporting changes in body mass index and weight change with changes in lung function. This European study recruited 3673 participants and monitored change in weight, BMI and lung function over 20 years. Moderate and high weight gain over 20 years was associated with accelerated lung function decline, while weight loss was related to its attenuation with the control of weight gain important for maintaining lung function in adult life. "Thank you very much".

\section{SPARKS}

The SPARKS are an American band formed in Los Angeles in 1967 by brothers Ron and Russell Mael. The music is accompanied by a theatrical stage presence, typified in the contrast between Russell's animated, hyperactive frontman antics and Ron's deadpan scowling on keyboards. This approach is similar to the contrasting approach employed by Miriam Barrecheguren and colleagues (see page 351) in the COPD SPARK study that investigated controlled and uncontrolled COPD as a predictor of future exacerbations. Patients with low impact and stability during weeks 1-12 were classified as controlled, and exacerbations were measured during a 52 week follow-up. Of 2044 patients included, 80\% were uncontrolled, with the rate of exacerbations lower and time-to-first exacerbation delayed in the controlled patients. Control is important and so we should follow Ron rather than Russell but find out for yourself by watching Ron and Russell in October at the Roundhouse in London.

\section{SHAZAM}

We all been driven mad by that tune we can't recognise, then along came Shazam to make our lives better. Music Information Retrieval (MIR) algorithms such as those used by Shazam match songs to a known database of content, but unfortunately can't recognise unknown songs, whereas the human brain can identify the artist performing a new song if familiar with the artist in question, and so the convolutional recurrent neural network was required (Nasrullah and Zhao https://arxiv.org/abs/ 1901.04555). In this issue of Thorax, Stock and colleagues (see page 306) use convolutional neural networks (CNN) to improve risk prediction of solitary pulmonary nodules. The Lung Cancer Prediction-CNN (LCP-CNN) was better than the Brock model with a significantly better AUC and only one false negative in contrast with the Brock model's six. So in future when you next look at a CT to decide what to do about an SPN maybe all you'll need to do is ask Shazam's big brother?

\section{(I CANT GET NO) ACTIVATION}

55 years ago Mick Jagger sang 'When I'm watchin' my TV and a man comes on and tells me, How white my shirts can be, But, he can't be a man 'cause he doesn't smoke, The same cigarettes as me'. What they probably both shared was some degree of airway's disease. If they also both shared alpha-1 antitrypsin deficiency (AAD) then activation, or not, of complement C3 may be have been able to separate them apart further. In this edition of Thorax (see page 321), O'Brien and colleagues show that concentrations of the $\mathrm{C} 3$ breakdown product $\mathrm{C} 3 \mathrm{~d}$ were increased in patients with $\mathrm{AAD}$, which was also associated with radiographic emphysema. Furthermore, C3d levels dropped when patients took AAD replacement therapy. This study will do better than 'the man come on the radio' but should fire your imagination about the use of biomarkers for AAD.

(C) Author(s) (or their employer(s)) 2020. No commercial re-use. See rights and permissions. Published by BMJ. 